\title{
Fisiologia e produção da soja tratada com cinetina e cálcio sob deficit hídrico e sombreamento
}

\author{
Samuel Luiz Fioreze ${ }^{(1)}$, João Domingos Rodrigues(2), João Paulo Costa Carneiro(3), \\ André do Amaral Silva(4) e Marcelo Bruno Lima(4)
}

\begin{abstract}
(1)Universidade Federal de Santa Catarina, Departamento de Ciências Agrárias, Caixa Postal 101, CEP 89520-000 Curitibanos, SC, Brasil. E-mail: s.fioreze@ufsc.br (2)Universidade do Estado de São Paulo (Unesp), Instituto de Biociências, Departamento de Botânica, Caixa Postal 510, CEP 18618-970 Botucatu, SP, Brasil. E-mail: mingo@ibb.unesp.br (3)Universidade Estadual de Londrina, Departamento de Agronomia, Caixa Postal 10.011, CEP 86057-970 Londrina, PR, Brasil. E-mail: joaopaulo_carneiro@yahoo.com.br (4)Unesp, Faculdade de Ciências Agronômicas, Departamento de Produção e Melhoramento Vegetal, Caixa Postal 237, CEP 18610-307 Botucatu, SP, Brasil. E-mail: andredoamaralsilva@yahoo.com.br, marcelob.lima@yahoo.com.br
\end{abstract}

Resumo - O objetivo deste trabalho foi avaliar o efeito da cinetina e do cálcio sobre as características fisiológicas e produtivas de plantas de soja submetidas a estresses por deficit hídrico e sombreamento na fase de florescimento. Utilizou-se o delineamento de blocos ao acaso, em arranjo de parcelas subdivididas com quatro repetições. Plantas de soja cultivadas em vasos de $38 \mathrm{dm}^{3}$ foram submetidas à aplicação de cálcio e cinetina, de forma isolada e combinada, no início do florescimento e, em seguida, submetidas a estresse por deficit hídrico e por sombreamento por 12 dias. Após o período de estresse, as plantas foram conduzidas até a maturação com suprimento adequado de água e radiação. A aplicação de cálcio e cinetina promoveu a manutenção do conteúdo relativo de água nas plantas, após quatro dias de deficit hídrico. O extravasamento de eletrólitos celulares, medido ao final do período de estresse, foi menor em plantas tratadas com cálcio e cinetina. A assimilação de $\mathrm{CO}_{2}$ foi reduzida pela imposição do estresse, principalmente do deficit hídrico, e a produção de grãos nos dois ambientes foi reduzida na mesma intensidade.

Termos de indexação: Glycine max, ácido abscísico, assimilação de $\mathrm{CO}_{2}$, florescimento, hormônios vegetais.

\section{Physiology and yield of soybean treated with kinetin and calcium under drought and shade conditions}

\begin{abstract}
The objective of this work was to evaluate the effects of kinetin and calcium applications on the physiologic and productive traits of soybean plants, subjected to drought and shade conditions, at flowering. A randomized complete block design was used, in a split-plot arrangement, with four replicates. Soybean plants cultivated in $38 \mathrm{dm}^{3}$ pots were sprayed with calcium and kinetin, alone or mixed, and subjected to drought and shade during 12 days. After stress period, plants were cultivated under appropriate water and light availability. Calcium and kinetin application resulted in maintenance of the relative water content after four days of drought beginning. Membrane damage, measured at the end of stress period, was lower in plants sprayed with calcium and kinetin. $\mathrm{CO}_{2}$ assimilation diminished by stress condition, mainly under drought, and grain yield decreased at the same intensity in both environments.
\end{abstract}

Index terms: Glycine max, abscisic acid, $\mathrm{CO}_{2}$ assimilation, flowering, plant hormones.

\section{Introdução}

A ocorrência de abortamento de grande quantidades de flores e vagens é comumente observada na cultura da soja. Em condições normais de cultivo, a percentagem de vagens fixadas varia de 20 a 40\% (Jiang \& Egli, 1993). Em estudo de Liu et al. (2004), o controle da abscisão de estruturas reprodutivas na cultura da soja foi atribuído à disponibilidade de fotoassimilados e nutrientes, principalmente do cálcio, e à concentração endógena de alguns hormônios vegetais, como o ácido abscísico e a citocinina. Essas características são influenciadas pelo ambiente de cultivo, em que o abortamento de estruturas reprodutivas pode ser observado em condições adversas de ambiente, como deficit hídrico, altas temperaturas ou baixa intensidade luminosa. Estas condições provocam limitações à divisão e ao alongamento celular ou decréscimo do acúmulo de matéria seca, em grãos em formação, conforme a época de ocorrência (Fageria et al., 2006).

$\mathrm{O}$ balanço entre a atividade de hormônios promotores e inibidores é importante para o 
desenvolvimento reprodutivo de plantas. A citocinina e o ácido abscísico são considerados os hormônios mais determinantes para o desenvolvimento reprodutivo, em condições normais e de estresse ambiental (Liu et al., 2004). Os efeitos da citocinina são determinantes para o processo de divisão celular, característico da primeira fase do desenvolvimento de sementes e o período mais crítico do desenvolvimento do embrião (Westgate \& Peterson, 1993). Assim, pode-se considerar que a definição do potencial de força de dreno de tecidos reprodutivos jovens é dependente da atividade da citocinina. A aplicação de 6-benzilaminopurina (BAP) a racemos individuais de plantas de soja resulta na redução do abortamento das flores, em condições de bom suprimento hídrico (Cho et al., 2002). No entanto, a ocorrência de deficit hídrico causa redução da concentração de citocinina em folhas e o abortamento de estruturas reprodutivas de trigo (Yang et al., 2003).

$\mathrm{O}$ cálcio atua como mensageiro em processos metabólicos relacionados ao crescimento e desenvolvimento de plantas, como a divisão, diferenciação, polaridade e alongamento celular, fotomorfogênese, defesa e resposta da planta a estresses bióticos e abióticos (White \& Broadley, 2003). Além dos efeitos sobre o crescimento do tubo polínico (Krichevsky et al., 2007), os efeitos do cálcio na fertilização de flores incluem a atração, a comunicação a curtas distâncias, a fusão celular e a sinalização, de modo que o primeiro evento celular, observado após a fusão de gametas, é o aumento da concentração citossólica de cálcio, seguido pelo aumento da taxa de divisão celular (Ge et al., 2007), o que evidencia sua importância no desenvolvimento reprodutivo de plantas.

O movimento de cálcio no interior das plantas é restrito a regiões apoplásticas e é altamente dependente do fluxo transpiratório, que é baixo em tecidos jovens (White \& Broadley, 2003). O fluxo de cálcio para estruturas reprodutivas em fases críticas do desenvolvimento é, portanto, dependente da diferenciação vascular e da taxa de movimento de solutos no xilema. Assim, a ocorrência de condições ambientais que limitam o fluxo transpiratório de plantas pode induzir à deficiência de cálcio em estruturas reprodutivas, de modo a reduzir a quantidade de vagens fixadas.
O objetivo deste trabalho foi avaliar o efeito da cinetina e do cálcio sobre as características fisiológicas e produtivas de plantas de soja submetidas a estresses por deficit hídrico e sombreamento na fase de florescimento.

\section{Material e Métodos}

O experimento foi instalado em cultivo protegido, no Departamento de Horticultura da Faculdade de Ciências Agronômicas de Botucatu, de janeiro a maio de 2012, em casa de vegetação construída em vidro, com sistema de controle automático da temperatura e umidade relativa do ar. Utilizou-se o delineamento experimental de blocos ao acaso, em arranjo de parcelas subdivididas, com quatro repetições. As parcelas foram formadas pela aplicação de estresse por deficit hídrico e por sombreamento, com duração de 12 dias a partir do estádio fenológico R2 (Fehr \& Caviness, 1977), além de um ambiente controle sem estresse. As subparcelas foram formadas pela aplicação de cinetina e de cálcio, na forma isolada ou combinada, no estádio R2. Cada unidade experimental foi formada por um vaso de polietileno, com volume de $38 \mathrm{dm}^{3}$, preenchido com Latossolo Vermelho distroférrico de textura média (Santos et al., 2006) e cultivado com seis plantas, no total de 48 vasos. Quatro plantas de cada subparcela foram destinadas à coleta de material, durante o período de estresse, e o restante à avaliação dos componentes da produção, ao final do ciclo da cultura.

O solo utilizado apresentava: matéria orgânica, $19 \mathrm{~g} \mathrm{dm}^{-3} ; \mathrm{pH}\left(\mathrm{CaCl}_{2}\right), 6,1 ; \mathrm{Ca}, 34 \mathrm{mmol}_{\mathrm{c}} \mathrm{dm}^{-3} ; \mathrm{Mg}$, $24 \mathrm{mmol}_{\mathrm{c}} \mathrm{dm}^{-3}$; Al, 0,0 $\mathrm{cmol}_{\mathrm{c}} \mathrm{dm}^{-3}$; K, $3 \mathrm{mmol}_{\mathrm{c}} \mathrm{dm}^{-3}$; $\mathrm{P}$ (Mehlich-1), $5 \mathrm{mg} \mathrm{dm}^{-3}$; e saturação por bases de $73 \%$. Antes da semeadura, o solo foi adubado com $687 \mathrm{mg} \mathrm{dm}^{-3}$ de $\mathrm{P}_{2} \mathrm{O}_{5}$ (superfosfato simples) e $78 \mathrm{mg} \mathrm{dm}^{-3}$ de $\mathrm{K}_{2} \mathrm{O}$ (cloreto de potássio). Bactérias do gênero Bradyrhizobium foram inoculadas às sementes tratadas com inseticida (thiamethoxan) e fungicida (carboxim+thiram). A cultivar de soja utilizada foi a BRS 245 RR. Semearam-se 12 sementes em cada vaso, de modo que, após o desbaste, restassem duas fileiras com três plantas cada, bem distribuídas na área do vaso. Após o estabelecimento das folhas, o solo dos vasos foi recoberto com uma camada de feno (capim-tifton), para limitar as perdas de água e o crescimento de plantas invasoras. Nos estádios V4 e

Pesq. agropec. bras., Brasília, v.48, n.11, p.1432-1439, nov. 2013 DOI: 10.1590/S0100-204X2013001100003 
V8 de desenvolvimento da cultura (Fehr \& Caviness, 1977), realizaram-se duas adubações de cobertura, com uma solução completa de Hogland \& Arnon (1950).

As plantas foram conduzidas com suprimento adequado de água e luz até o estádio R2 de desenvolvimento, aos 42 dias após a emergência (DAE). No dia anterior à indução do estresse ambiental, realizou-se a aplicação via foliar de $400 \mathrm{~g} \mathrm{ha}^{-1}$ de cinetina (citocinina sintética) e de 235,8 $\mathrm{g} \mathrm{ha}^{-1}$ de cálcio, com o uso de um pulverizador de barras, com pressão de $\mathrm{CO}_{2}$, e bicos do tipo leque (110-02), ajustado para um volume de calda de 150 $\mathrm{L} \mathrm{ha}^{-1}$. O adjuvante utilizado nas aplicações foi óleo vegetal a $0,5 \%$. O controle recebeu a aplicação de água e adjuvante, para uniformizar a superfície de molhamento.

Para a imposição do estresse por sombreamento, as plantas foram recobertas com tela de sombreamento posicionada a um metro de distância do dossel, com capacidade de reter $80 \%$ da luz incidente. O deficit hídrico foi imposto de forma a desenvolver três ciclos de estresse, com duração de quatro dias. No início de cada ciclo, a irrigação foi suspensa até que a taxa de assimilação líquida de carbono das plantas atingisse valores próximos de zero, quando a irrigação era retomada e outro ciclo iniciado. Após o período de estresse (12 dias), todos os tratamentos foram conduzidos sob as mesmas condições de suprimento de água e intensidade luminosa, até o final do ciclo da cultura. O fluxo de fótons fotossinteticamente ativos foi monitorado durante o período de estresse, com um sensor localizado na câmara de um medidor portátil de fotossíntese modelo Li 6200 (Licor, Inc., Lincoln, NE, EUA). No mesmo período, a umidade do solo foi monitorada pelo método gravimétrico.

O conteúdo relativo de água nas folhas (CRA) foi determinado durante o período de estresse, a intervalos de dois dias, de 0 aos 12 dias após a aplicação dos tratamentos (DAA), e dois dias após a recuperação. No período entre 4:30 e 5:30 h, determinou-se a massa de matéria fresca, imediatamente após a coleta $(\mathrm{MF})$ e, após seis horas de imersão em água à $25^{\circ} \mathrm{C}$, a massa de matéria túrgida (MT) e, por fim, a massa de matéria seca (MS) de discos foliares. O CRA foi definido com a fórmula $\mathrm{CRA}=(\mathrm{MF}-\mathrm{MS}) /(\mathrm{MT}-\mathrm{MS})$ $\mathrm{x}$ 100. No mesmo período, as trocas gasosas foram determinadas com um medidor portátil de fotossíntese modelo Li 6200 (Licor, Inc., Lincoln, NE, EUA). No período entre 9:00 e 11:00 h, foram determinadas: a taxa de assimilação líquida de carbono (A), a taxa de transpiração (E), a condutância estomática $(g s)$ e a temperatura das folhas.

No último dia de estresse, determinou-se a tolerância protoplasmática à dessecação foliar, com base na liberação de eletrólitos pelas membranas, a qual é um indicativo dos danos provocados por espécies reativas de oxigênio às membranas celulares. A condutividade elétrica de uma solução de água deionizada, que continha 10 discos foliares imersos por 24 horas, foi denominada de condutividade atual. Após uma hora em banho-maria a $100^{\circ} \mathrm{C}$, a condutividade elétrica da solução, denominada de condutividade total, foi novamente determinada. Ao final do ciclo da cultura, os componentes da produção e a produção de grãos foram determinados em duas plantas por vaso. Os componentes da produção foram divididos nos três grupos seguintes: número total de vagens e o número de vagens nos terços inferior, médio e superior da planta; número total de grãos por planta nos terços inferior, médio e superior; e massa de grãos por planta nos três terços. Os dados foram submetidos à análise de variância e as médias foram contrastadas pelo teste t de Student, a 5\% de probabilidade, quando detectadas variações significativas.

\section{Resultados e Discussão}

Plantas submetidas à restrição do suprimento de água apresentaram os menores valores de CRA durante o período (Figura $1 \mathrm{C}$ ). Os menores valores de CRA, em folhas de plantas submetidas a deficit hídrico, foram observados nos dias finais de cada ciclo de estresse e acompanharam a redução da disponibilidade de água no solo (Figura 1 B). O período entre 12 e 14 DAA caracterizou-se como período de recuperação, com todos os tratamentos nas mesmas condições de luz e suprimento hídrico. Nos ambientes controle e sombreado, o CRA das plantas permaneceu constante, tendo sido superior ao de plantas sob deficit hídrico.

Plantas tratadas com cálcio, isolada ou conjuntamente com a cinetina, apresentaram maiores valores de CRA ao final do primeiro ciclo de deficit hídrico (4 DAA), principalmente na aplicação conjunta (Tabela 1). Nos ambientes controle e sombreado, não houve efeito da aplicação 

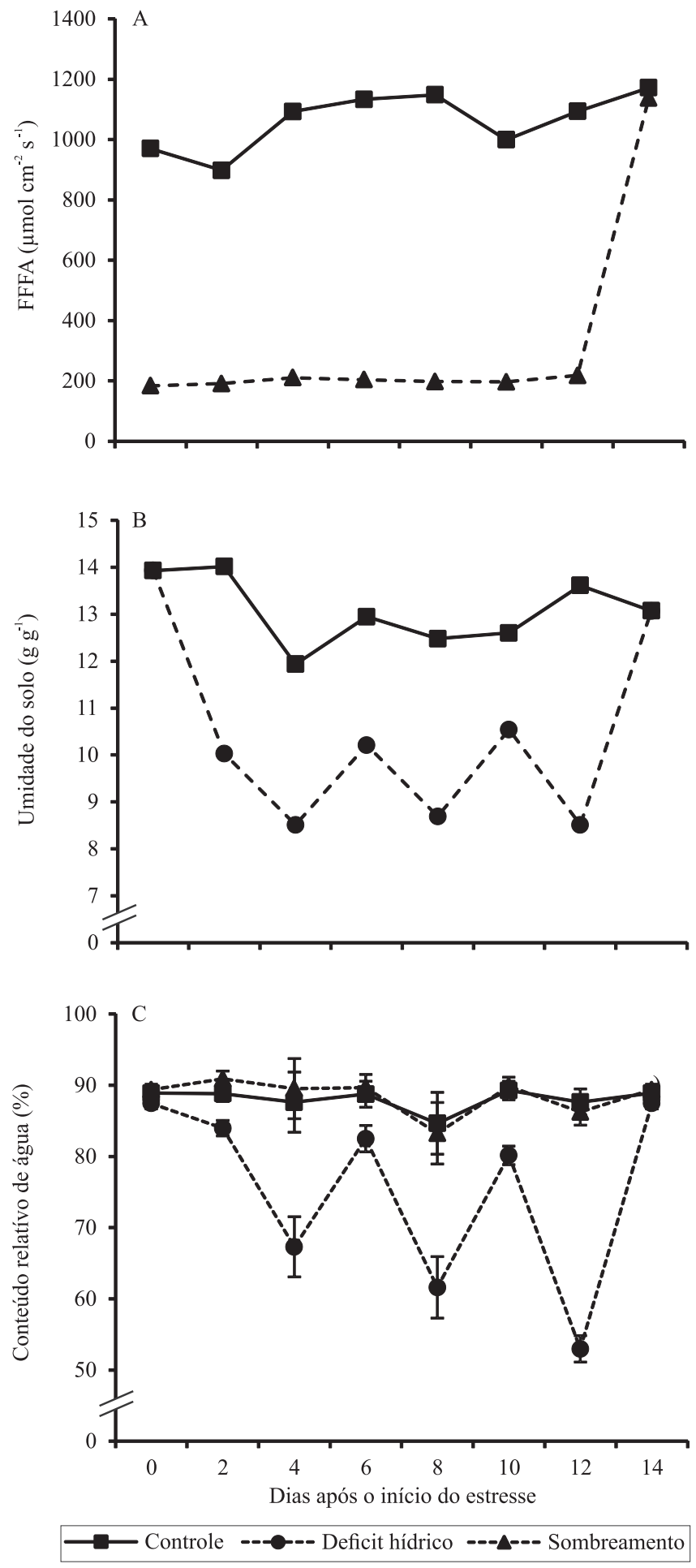

Figura 1. Fluxo de fótons fotossinteticamente ativos (A), umidade gravimétrica do solo $(\mathrm{B})$ e conteúdo relativo de água (C) de folhas plantas de soja BRS $245 \mathrm{RR}$, durante o período de estresse ambiental no estádio R2. Os símbolos representam a média das quatro repetições. As barras verticais representam a diferença mínima significativa (DMS) pelo teste $\mathrm{t}$ de Student, a 5\% de probabilidade. de cálcio e cinetina. Nos demais dias de estresse hídrico, o efeito da aplicação de cálcio e cinetina não foi observado. Os efeitos do cálcio e da cinetina sobre a manutenção do CRA parecem ocorrer de forma isolada e não conjunta, visto que o efeito da aplicação combinada de ambos não foi superior ao da aplicação isolada.

Valores elevados de conteúdo relativo de água nas folhas permitem a manutenção do metabolismo celular durante eventos de estresse (Jones, 2007). Com os resultados do presente trabalho (Tabela 1), pode-se inferir que os efeitos do cálcio e da cinetina, sobre a manutenção do estado hídrico foliar, ocorrem por vias diferentes e independentes.

A manutenção do status hídrico das plantas, por meio do fechamento estomático, ocorre em resposta à sinalização desencadeada pelo ácido abscísico (Hong-Bo et al., 2008). Assim, como mensageiro secundário, o cálcio presente em maiores concentrações nas folhas pode aumentar a eficiência da ação do ácido abscísico sobre o controle estomático das perdas de água.

Outra estratégia para a manutenção do turgor celular pode estar associada ao ajustamento osmótico, por meio do acúmulo de compostos osmoticamente ativos e não nocivos nas células. Em um estudo com plantas mutantes de grama rasteira (Agrostis stolonifera), com superexpressão de genes associados com a biossíntese de citocinina, Merewitz et al. (2012) observaram que o acúmulo de citocinina está diretamente relacionado ao acúmulo de solutos compatíveis, como prolina, glicina, alanina, sacarose, frutose e maltose que, por sua vez, estão relacionados ao ajuste osmótico.

Tabela 1. Conteúdo relativo de água nas folhas (médias das quatro repetições) aos 4 DAA, em plantas de soja BRS 245 RR, para o desdobramento do efeito do estresse ambiental e da aplicação de cálcio, cinetina e cálcio + cinetina, no estádio R2 ${ }^{(1)}$.

\begin{tabular}{lcccc}
\hline Ambiente & \multicolumn{4}{c}{ Conteúdo relativo de água (\%) 4 DAA ${ }^{(2)}$} \\
\cline { 2 - 5 } & Controle & $\mathrm{Ca}$ & $\mathrm{CK}$ & $\mathrm{Ca}+\mathrm{CK}$ \\
\hline Controle & $87,9 \mathrm{aA}$ & $88,7 \mathrm{aA}$ & $87,2 \mathrm{aA}$ & $86,7 \mathrm{aA}$ \\
Deficit hídrico & $52,3 \mathrm{bC}$ & $75,6 \mathrm{bA}$ & $66,0 \mathrm{bB}$ & $75,2 \mathrm{bA}$ \\
Sombreamento & $87,4 \mathrm{aA}$ & $90,3 \mathrm{aA}$ & $87,8 \mathrm{aA}$ & $92,5 \mathrm{aA}$ \\
\hline DMS & \multicolumn{4}{c}{8,61} \\
\hline
\end{tabular}

(1)Médias seguidas por letras iguais, minúsculas nas colunas e maiúsculas nas linhas, não diferem entre si, pelo teste t de Student, a 5\% de probabilidade. ${ }^{(2)}$ DAA, dias após a aplicação. 
Os valores da taxa de assimilação líquida de carbono (A), no ambiente com deficit hídrico (Figura $2 \mathrm{~A}$ ), variaram com a disponibilidade de água no solo e o conteúdo relativo de água nas folhas, durante os três ciclos de estresse. O efeito do sombreamento em A foi observado logo no primeiro dia de estresse. Entretanto, o sombreamento resultou em valores intermediários de A em relação ao ambiente controle e sob deficit hídrico. O comportamento observado é típico de espécies com metabolismo fotossintético $\mathrm{C}_{3}$, com plantas mais adaptadas a condições de baixa luminosidade, do que a restrições hídricas, em comparação com plantas com metabolismo fotossintético $\mathrm{C}_{4}$ (Zhu et al., 2010).

Os maiores valores de transpiração foliar (E) em plantas de soja foram observados no ambiente controle (Figura 2 B). A partir do segundo ciclo de deficit, os valores de E para este ambiente foram os menores observados. A transpiração de plantas submetidas ao sombreamento foi intermediária entre o controle e o deficit hídrico. A redução da transpiração de plantas sob deficit hídrico é consequência do fechamento estomático, como estratégia para limitar as perdas de água. Em contrapartida, reduzidos valores de
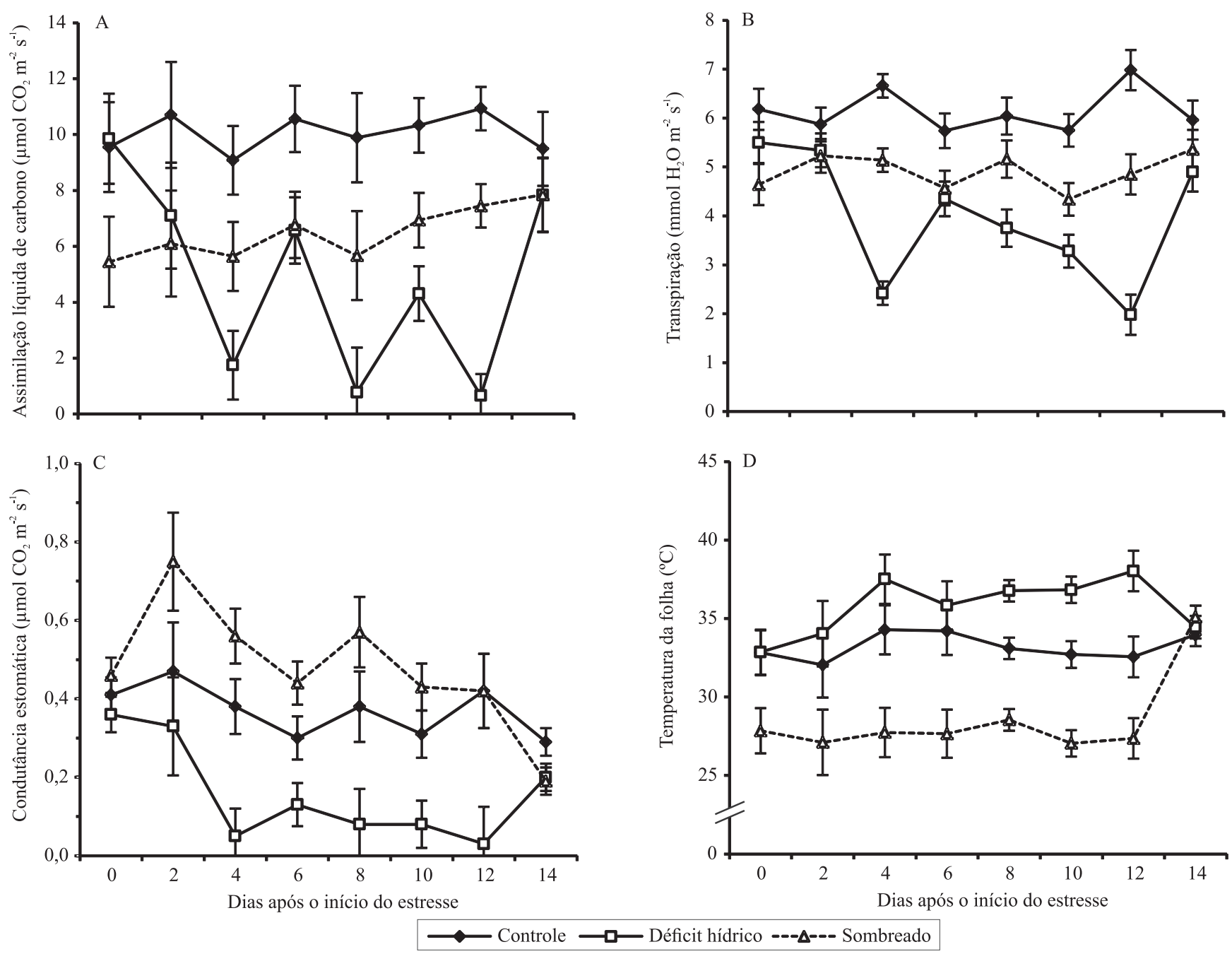

Figura 2. Assimilação líquida de carbono (A), taxa de transpiração (B), condutância estomática (C) e temperatura da folha (D), em folhas de plantas de soja BRS 245 RR, para o efeito do estresse ambiental no estádio R2. Os símbolos representam a média das quatro repetições. As barras verticais representam a diferença mínima significativa (DMS), pelo teste t de Student, a $5 \%$ de probabilidade. 
transpiração foliar, em plantas sombreadas, não resultam do fechamento estomático, mas sim da redução do deficit de pressão de vapor no ambiente, visto que a difusão de água para a atmosfera é independente da difusão de $\mathrm{CO}_{2}$. Este fato pode ser confirmado pelos maiores valores de condutância estomática (gs) observados em plantas sombreadas, enquanto os menores valores são observados em plantas com deficit hídrico (Figura $2 \mathrm{C}$ ).

A redução da disponibilidade hídrica resultou em maiores valores de temperatura foliar (Figura 2 D). A transpiração foliar é essencial para dissipar o excesso de energia absorvida pelas folhas, e a redução da disponibilidade de água limita o controle da temperatura no dossel da planta (Zhu et al., 2010). Valores intermediários de temperatura foliar foram observados no ambiente controle. Apesar das limitações ao metabolismo fotossintético acarretadas pelo estresse hídrico e pela temperatura, o impedimento parece ocorrer por vias diferentes nos dois ambientes. Sob deficit hídrico, a inibição da fotossíntese ocorreu em razão do fechamento estomático que limitou a difusão de $\mathrm{CO}_{2}$ para as células do mesofilo foliar (Figura $1 \mathrm{C}$ ). No caso do ambiente sombreado, a limitação fotossintética ocorreu pela redução da disponibilidade de energia luminosa (Figura $1 \mathrm{~A}$ ), visto que a entrada de $\mathrm{CO}_{2}$ no mesofilo não foi um fator limitante (Figura $1 \mathrm{C}$ ).

O fluxo transpiratório das plantas foi afetado tanto em condições de deficit hídrico quanto de sombreamento (Figura 2 B). Sabe-se que o movimento de cálcio via xilema segue o fluxo transpiratório e é igualmente afetado quando a transpiração é reduzida em condições ambientais desfavoráveis (White \& Broadley, 2003). Assim, a fixação de estruturas reprodutivas em plantas de soja, em ambientes sombreados ou com deficit hídrico, pode ser limitada pela baixa disponibilidade de assimilados e também pela limitação da redistribuição de cálcio para estas estruturas. A aplicação de cálcio e de cinetina não afetou as trocas gasosas de plantas de soja nos ambientes estudados.

Em plantas não tratadas com cálcio ou cinetina, o maior extravasamento de eletrólitos, medido pela condutividade livre, foi observado nas plantas submetidas a deficit hídrico, seguidas das plantas sem estresse (controle) e das plantas sombreadas (Tabela 2). Em plantas tratadas com cálcio ou cinetina de forma isolada, não houve diferenças entre plantas no ambiente controle e em deficit hídrico. Quanto à aplicação conjunta de cálcio e cinetina, a maior condutividade livre foi observada no ambiente controle, e não houve diferença entre plantas submetidas a deficit hídrico e sombreamento. Em plantas submetidas a deficit hídrico, os maiores valores de condutividade foram observados nas não tratadas, enquanto os menores valores foram observados nas plantas com ambos os tratamentos. A manutenção da integridade de membranas celulares, em resposta ao ataque de radicais livres, está relacionada ao balanço entre citocinina e ácido abscísico (ABA) nas folhas (Nishiyama et al., 2011). A maior atividade das enzimas do estresse oxidativo ocorre em resposta a altas concentrações de citocinina em plantas de soja (Gidrol et al., 1994). Rivero et al. (2007) verificaram aumento da atividade da enzima catalase nos peroxissomos de plantas transgênicas de tabaco com elevada síntese de citocinina, as quais apresentaram maior tolerância ao estresse por deficit hídrico do que plantas selvagens.

$\mathrm{O}$ efeito isolado e, principalmente, o efeito sinérgico do cálcio e da citocinina sobre a redução do extravasamento de eletrólito pode estar relacionado a mecanismos de sinalização no sistema de defesa da célula contra o ataque de radicais livres. De acordo com Yan et al. (2006), a sinalização celular em resposta à presença de espécies reativas de oxigênio tem a participação do cálcio como mensageiro secundário, o qual ativa enzimas do estresse oxidativo de forma direta ou amplifica o sinal, por meio da ativação da calmodulina.

Tabela 2. Extravasamento de eletrólito em folhas de soja BRS 245 RR, para o desdobramento do efeito do estresse ambiental e da aplicação de cálcio, cinetina e cálcio + cinetina no estádio R2 e comparação entre ambientes (médias das quatro repetições). ${ }^{(1)}$

\begin{tabular}{lccccc}
\hline Ambiente & \multicolumn{4}{c}{ Condutividade livre $\left(\mu \mathrm{sm}^{-1}\right)$} & $\mathrm{CT}$ \\
\cline { 2 - 5 } & Controle & $\mathrm{Ca}$ & $\mathrm{CK}$ & $\mathrm{Ca}+\mathrm{CK}$ & $\left(\mu \mathrm{s} \mathrm{cm}^{-1}\right)$ \\
\hline Controle & $131,9 \mathrm{bA}$ & $122,8 \mathrm{abA}$ & $132,0 \mathrm{aA}$ & $156,0 \mathrm{aA}$ & $363,25 \mathrm{~b}$ \\
Deficit hídrico & $229,5 \mathrm{aA}$ & $164,5 \mathrm{aB}$ & $147,8 \mathrm{aB}$ & $87,1 \mathrm{bC}$ & $447,12 \mathrm{c}$ \\
Sombreamento & $60,7 \mathrm{cA}$ & $79,2 \mathrm{bA}$ & $74,5 \mathrm{bA}$ & $46,5 \mathrm{bA}$ & $227,19 \mathrm{a}$ \\
\hline DMS & \multicolumn{5}{c}{59,25} \\
\hline
\end{tabular}

${ }^{(1)}$ Médias seguidas por letras iguais, minúsculas nas colunas e maiúsculas nas linhas, não diferem entre si, pelo teste t de Student, a 5\% de probabilidade. CT, condutividade total. 
As plantas submetidas a deficit hídrico apresentaram maiores valores de condutividade total da solução de discos foliares (Tabela 2), enquanto os menores valores foram observados para plantas sombreadas. Valores intermediários foram observados para o ambiente controle. $\mathrm{O}$ aumento da concentração de eletrólitos em células foliares, medido por meio da condutividade total dos discos, pode representar um mecanismo que evita a dessecação dos tecidos, em razão da redução do componente osmótico do potencial hídrico foliar. Este comportamento é observado na cultura da soja, em que a ocorrência de ajustamento osmótico é variável entre genótipos e nem sempre é suficiente para a manutenção do estado hídrico foliar (James et al., 2008), como pode ter ocorrido no presente estudo.

Tanto o estresse por deficit hídrico quanto o estresse por sombreamento reduziram os componentes diretos da produção (número de vagens, número de grãos e peso médio de grãos), sem diferir entre si (Tabela 3). A massa de cem grãos foi maior em plantas submetidas a deficit hídrico, o que pode ser uma característica adaptativa de plantas que passaram por situações de seca no período de florescimento, como um mecanismo compensatório em razão da redução do número de grãos formados. Os altos números de vagens chochas e de percentagem de vagens viáveis são uma indicação de que os efeitos nocivos do deficit hídrico foram mais intensos sobre o abortamento de flores do que de grãos dentro da vagem. O terço inferior das plantas submetidas à restrição hídrica foi o mais afetado, tendo apresentado menor número de vagens e grãos. Nessas plantas, a maior proporção da produção foi observada no terço superior da planta (Tabela 3). A aplicação de cálcio e cinetina não afetou os componentes da produção nem a produção das plantas.

A redução dos componentes de produção e do rendimento de grãos por planta é um reflexo claro da limitação fotossintética, proporcionada pela ocorrência de estresse ambiental no início do período de florescimento (Figura $2 \mathrm{~A}$ ), por meio da limitação hídrica ou do sombreamento (Figura 1). Deve-se destacar, contudo, que a limitação fotossintética em plantas submetidas a deficit hídrico foi mais intensa do que a imposta pelo sombreamento. Mesmo tendo afetado o metabolismo fotossintético a intensidades diferentes, o efeito das duas formas de estresse, quanto à produção de grãos, foi semelhante. $\mathrm{O}$ cálcio é um nutriente que se movimenta basicamente em regiões apoplásticas de tecidos vegetais (White \& Broadley, 2003). Em áreas de produção de soja, o objetivo da aplicação foliar com cálcio é o suprimento direto a estruturas reprodutivas, visto que os nutrientes presentes nas folhas dificilmente serão redistribuídos. A baixa vascularização de estruturas reprodutivas jovens (Mondal et al., 2011), associada à baixa taxa de transpiração dessas estruturas (White \& Broadley, 2003), resulta em limitações ao fluxo de cálcio, seja de raízes ou mesmo de folhas, que podem ser agravadas principalmente em condições de limitações ao fluxo de água no interior da planta. Assim, para que a aplicação de cálcio seja efetiva, seus alvos principais devem ser os botões florais e flores em desenvolvimento, porém o efeito guarda-chuva provocado pela grande quantidade de folhas em plantas de soja na fase reprodutiva - representa uma barreira, pois torna difícil que a solução aplicada atinja o alvo, o que precisa ser resolvido pela tecnologia de aplicação.

Tabela 3. Componentes de produção e produção de grãos, em plantas de soja BRS 245 RR (médias das quatro repetições), para o efeito do estresse ambiental no estádio R2. ${ }^{(1)}$

\begin{tabular}{|c|c|c|c|c|c|c|c|c|c|c|c|c|c|c|}
\hline Ambiente & NVP & NVINF & NVMED & NVSUP & $\mathrm{NVCH}$ & $\% \mathrm{VV}$ & NGP & NGINF & NGMED & NGSUP & MGP & MGINF & MGSUP & MCG \\
\hline Controle & $41,3 \mathrm{a}$ & $6,6 \mathrm{a}$ & $20,1 \mathrm{a}$ & $14,6 \mathrm{a}$ & $5,9 \mathrm{a}$ & $85,3 b$ & $77,9 \mathrm{a}$ & $10,2 \mathrm{a}$ & $40,8 \mathrm{a}$ & $26,9 \mathrm{a}$ & $12,2 \mathrm{a}$ & $1,6 \mathrm{a}$ & $4,2 \mathrm{a}$ & $15,7 \mathrm{~b}$ \\
\hline Deficit hídrico & $27,7 b$ & $2,4 \mathrm{c}$ & $14,8 b$ & $10,5 b$ & $2,3 \mathrm{c}$ & $91,5 \mathrm{a}$ & $54,6 \mathrm{~b}$ & $3,2 \mathrm{c}$ & $29,5 \mathrm{~b}$ & $21,9 b$ & $9,8 \mathrm{~b}$ & $0,6 \mathrm{c}$ & $4,0 \mathrm{a}$ & $18,0 \mathrm{a}$ \\
\hline Sombreamento & $29,3 b$ & $3,7 \mathrm{~b}$ & $16,7 \mathrm{ab}$ & $9,0 \mathrm{~b}$ & $3,8 \mathrm{~b}$ & $86,8 \mathrm{~b}$ & $57,2 b$ & $5,2 \mathrm{~b}$ & $33,7 \mathrm{~b}$ & $18,3 \mathrm{~b}$ & $9,3 b$ & $0,9 \mathrm{~b}$ & $3,0 \mathrm{~b}$ & $16,2 \mathrm{~b}$ \\
\hline DMS & 2,71 & 0,89 & 3,56 & 1,82 & 0,96 & 2,64 & 8,52 & 1,67 & 6,9 & 3,79 & 1,46 & 0,24 & 0,75 & 0,9 \\
\hline
\end{tabular}

${ }^{(1)}$ Médias seguidas por letras iguais não diferem entre si, pelo teste $t$ de Student, a $\%$ de probabilidade. NVP, número de vagens por planta; NVINF, número de vagens no terço inferior; NVMED, número de vagens no terço médio; NVSUP, número de vagens no terço superior; NVCH, número de vagens chochas; \%VV, percentagem de vagens viáveis; NGP, número de grãos por planta; NGINF, número de grãos no terço inferior; NGMED, número de grãos no terço médio; NGSUP, número de grãos no terço superior; MGP, massa de grãos por planta; MGINF, massa de grãos no terço inferior; MGSUP, massa de grãos no terço superior; MCG, massa de cem grãos. 


\section{Conclusões}

1. Em condição de estresse ambiental, particularmente com deficit hídrico, o fornecimento exógeno de cálcio e cinetina para plantas de soja promove a manutenção do conteúdo relativo de água e a redução do extravasamento de eletrólitos celulares;

2. A aplicação de cálcio e cinetina a plantas de soja com deficit hídrico e sombreamento não aumenta a produção final de grãos.

\section{Referências}

CHO, K.; SUH, S.K.; PARK, H.K.; WOOD, A. Impact of 2,4-DP and BAP upon pod set and seed yield in soybean treated at reproductive stages. Plant Growth Regulation, v.36, p.215-221, 2002. DOI: $10.1023 / \mathrm{A}: 1016590505449$

FAGERIA, N.K.; BALIGAR, V.C.; CLARK, R.B. Physiology of crop production. New York: The Haworth, 2006. 345p.

FEHR, W.R.; CAVINESS, C.E. Stages of soybean development. Ames: Iowa State University of Science and Technology, 1977. 11 p. (Special report, 80).

GE, L.L.; TIAN, H.Q.; RUSSELL, S.D. Calcium function and distribution during fertilization in angiosperms. American Journal of Botany, v.94, p.1046-1060, 2007. DOI: 10.3732/ ajb.94.6.1046.

GIDROL, X.; LIN, W.S.; DEGOUSEE, N.; YIP, S.F.; KUSH, A. Accumulation of reactive oxygen species and oxidation of cytokinin in germinating soybean seeds. European Journal of Biochemistry, v.224, p.21-28, 1994. DOI: 10.1111/j.1432-1033.1994.tb19990.x.

HOAGLAND, D.R.; ARNON, D.I. The water culture method for growing plants without soils. Berkeley: California Agricultural Experimental Station, 1950. 347p.

HONG-BO, S.; LI-YE, C.; MING-AN, S. Calcium as a versatile plant signal transducer under soil water stress. BioEssays, v.30, p.634-641, 2008. DOI: 10.1002/bies.20770.

JAMES, A.T.; LAWN, R.J.; COOPER, M. Genotypic variation for drought stress response traits in soybean. II. Inter-relations between epidermal conductance, osmotic potential, relative water content, and plant survival. Australian Journal of Agricultural Research, v.59, p.670-678, 2008. DOI: 10.1071/AR07160.

JIANG, H.; EGLI, D.B. Shade induced changes in flower and pod number and flower and fruit abscission in soybean. Agronomy Journal, v.85, p.221-225, 1993. DOI: 10.2134/agronj1993.00021 $962008500020011 \mathrm{x}$.

JONES, H.G. Monitoring plant and soil water status: established and novel methods revisited and their relevance to studies of drought tolerance. Journal of Experimental Botany, v.58, v.119-130, 2007. DOI: 10.1093/jxb/erl118.

KRICHEVSKY, A.; KOZLOVSKY, S.V.; TIAN, G.-W.; CHEN, M.-H.; ZALTSMAN, A.; CITOVSKY, V. How pollen tubes grow. Developmental Biology, v.303, p.405-420, 2007. DOI: 10.1016/j. ydbio.2006.12.003.
LIU, F.; JENSEN, C.R.; ANDERSEN, M.N. Pod set related to photosynthetic rate and endogenous $\mathrm{ABA}$ in soybeans subjected to different water regimes and exogenous $\mathrm{ABA}$ and $\mathrm{BA}$ at early reproductive stages. Annals of Botany, v.94, p.405-411, 2004. DOI: $10.1093 / \mathrm{aob} / \mathrm{mch} 157$.

MEREWITZ, E.B.; DU, H.; YU, W.; LIU, Y.; GIANFAGNA, T.; HUANG, B. Elevated cytokinin content in ipt transgenic creeping bentgrass promotes drought tolerance through regulating metabolite accumulation. Journal of Experimental Botany, v.63, p.1315-1328, 2012. DOI: 10.1093/jxb/err372.

MONDAL, M.M.A.; FAKIR, M.S.A.; AZAD-UD-DOULA PRODHAN, A.K.M.; ISMAIL, M.R.; ASHRAFUZZAMAN, M. Deflowering effect on vasculature and yield attributes in raceme of mungbean [Vigna radiata (L.) Wilczek]. Australian Journal of Crop Science, v.5, p.1339-1344, 2011.

NISHIYAMA, R.; WATANABE, Y.; FUJITA, Y.; LE, D.T.; KOJIMA, M.; WERNER, T.; VANKOVA, R.; YAMAGUCHI-SHINOZAKI, K.; SHINOZAKI, K.; KAKIMOTO, T.; SAKAKIBARA, H.; SCHMULLING, T.; TRAN, L.P. Analysis of cytokinin mutants and regulation of cytokinin metabolic genes reveals important regulatory roles of cytokinins in drought, salt and abscisic acid responses, and abscisic acid biosynthesis. Plant Cell, v.23, p.2169-2183, 2011. DOI: $10.1105 /$ tpc.111.087395.

RIVERO, R.M.; KOJIMA, M.; GEPSTEIN, A.; SAKAKIBARA, H.; MITTLER, R.; GEPSTEIN, S.; BLUMWALD, E. Delayed leaf senescence induces extreme drought tolerance in a flowering plant. Proceedings of the National Academy of Sciences of the United States of America, v.104, p.19631-19636, 2007. DOI: 10.1073/ pnas.0709453104.

SANTOS, H.G. dos; JACOMINE, P.K.T.; ANJOS, L.H.C. dos; OLIVEIRA, V.A. de; OLIVEIRA, J.B. de; COELHO, M.R.; LUMBRERAS, J.F.; CUNHA, T.J.F. (Ed.). Sistema brasileiro de classificação de solos. 2.ed. Rio de Janeiro: Embrapa Solos, 2006. $306 \mathrm{p}$.

WESTGATE, M.E.; PETERSON, C.M. Flower and pod development in water-deficient soybeans (Glycine max L. Merr.). Journal of Experimental Botany, v.44, p.109-117, 1993. DOI: 10.1093/jxb/44.1.109.

WHITE, P.J.; BROADLEY, M.R. Calcium in plants. Annals of Botany, v.92, p.487-511, 2003. DOI: 10.1093/aob/mcg164.

YAN, Y.; WEI, C.L.; ZHANG, W.R.; CHENG, H.; LIU, J. Cross-talk between calcium and reactive oxygen species signaling. Acta Pharmacologica Sinica, v.27, p.821-826, 2006. DOI: 10.1111/j.1745-7254.2006.00390.x.

YANG, J.C.; ZHANG, J.H.; WANG, Z.Q.; ZHU, Q.S.; LIU, J.J. Involvement of abscisic acid and cytokinins in the senescence and remobilization of carbon reserves in wheat subjected to water stress during grain filling. Plant Cell and Environment, v.26, p.1621-1631, 2003. DOI: 10.1046/j.1365-3040.2003.01081.x.

ZHU, X.-G.; LONG, S.P.; ORT, D.R. Improving photosynthetic efficiency for greater yield. Annual Review of Plant Biology, v.61, p.235-261, 2010. DOI: 10.1146/annurev-arplant-042809-112206.

Recebido em 13 de setembro de 2013 e aprovado em 30 de outubro de 2013

Pesq. agropec. bras., Brasília, v.48, n.11, p.1432-1439, nov. 2013 DOI: 10.1590/S0100-204X2013001100003 